\title{
Water Purification by Double Filtration Using Ceramic Filters
}

\author{
Faustine Abiriga $^{1} \&$ Sam Obwoya Kinyera ${ }^{1}$ \\ ${ }^{1}$ Department of Physics, Kyambogo University, Kyambogo, Kampala, Uganda \\ Correspondence: Sam Obwoya Kinyera, Department of Physics, Kyambogo University, P.O. Box 1, Kyambogo, \\ Kampala, Uganda. Tel: 256-414-288-329. E-mail: ksobwoya@yahoo.co.uk
}

Received: January 16, $2014 \quad$ Accepted: March 23, $2014 \quad$ Online Published: April 24, 2014
doi:10.5539/enrr.v4n2p92

\begin{abstract}
This paper presents the results of an experimental study on the effects of double filtration on the rate of water percolation and E. coli removal efficiency of ceramic water filters made from mixtures of different ratios of clay powder, fine sawdust and powder of grog. The results show that double filtration produces superior quality of filtered water compared to single filtration although the rate of water percolation is higher for single filtration.
\end{abstract}

Keywords: double filtration, grogs, hard wood sawdust, permeability, water percolation, water turbidity

\section{Introduction}

In Uganda, clean water coverage stands at $59 \%$ in rural areas and $65 \%$ in urban areas. Generally only $60 \%$ of the country's population has access to clean and safe water for domestic use (WHO/UNICEF, 2010). Most of the water resources in the countryside are contaminated with dissolved minerals and pathogenic organisms which can be highly infectious and disease-causing (Kosek et al., 2003). The major route of transmission of diseases such as cholera, typhoid, amoebic and bacillary dysentery and other diarrheal diseases to humans is through drinking contaminated water.

The Government of Uganda (GoU) and Non-Government Organizations (NGOs) have invested in projects aimed at supplying clean water to the rural and semi-urban areas with the view of curbing water borne diseases. For example, under the Poverty Eradication Action Plan (PEAP), provision of clean piped water, and the use of Chlorine Tablets to disinfect water are some of the major areas being addressed, but their coverage and use is still very low, respectively. Sources of firewood which could provide energy for boiling the contaminated water before use are dwindling (Uganda National Energy Balance, 2002) and electricity is expensive for the majority of Uganda's rural poor who live in the country side (Matovu, 2012).

A simple, acceptable, low-cost intervention at the household and community level can dramatically improve the microbial quality of household stored water (Sobsey, 2002). One such an intervention is by the use of ceramic water filters (CWF). A ceramic material is an inorganic, non-metallic material produced as a result of the action of heat and subsequent cooling (Kingery, Bowen, \& Uhlmann, 1976). Currently, the most widely implemented ceramic filter is the Potters for Peace design (US Center for Disease Control, 2012). It is effective at removing bacteria and the larger protozoans, but not at removing the viruses.

The purpose of this study was therefore to make ceramic water filter discs from local materials and use double filtration technique to study their effectiveness in improving the quality of filtered water including $E$. coli removal efficiency.

\section{Material and Methods}

\subsection{Materials}

The basic raws material used to make the ceramic water filters include ball clay minerals, grog and sawdust from hardwood. The ball-clay mineral was preferred because it exhibits high plasticity to hold the filter particles together and it has a greater dry mechanical strength when fired (Prajapati, 2002).

The hardwood sawdust was preferred to softwood sawdust because it does not cause bloating and results in a more uniform pore formation with fewer defects in the filter (Katherine et al., 2000).

The ball-clay mineral and hard wood sawdust were first cleaned, dried, crashed and sieved through $1 \mathrm{~mm}$ sieves to obtain the powders, respectively. Part of the powders of ball clay and hard wood sawdust were mixed in the 
ratio of $4: 3$ by volume and then processed through the normal procedures to a final ceramic product. This final product was later crashed and sieved through $1 \mathrm{~mm}$ sieves to obtain the powdered grogs.

\subsection{Processing of Ceramic Water Filters}

The raw materials; ball clay, grogs and hardwood sawdust powders, were mixed in proportions of 3:1:3, 4:1:3, 4:1:2, 5:1:2 and 5:2:1 respectively by volumes and then shaken thoroughly. Water was added to the mixtures up to $20 \%$ by weight to improve on their workability. The mixtures were then compacted to a pressure of $200 \mathrm{kN}$ into cylindrical discs of diameter $8 \mathrm{~cm}$ and thickness $5 \mathrm{~mm}$ using a hydraulic laboratory press-PW40. Ten pieces of each composition ratio were made. The green bodies were air dried after which they were fired gradually to $850{ }^{\circ} \mathrm{C}$. This temperature was maintained for six hours to allow the body to mature into finished ceramic water filter discs.

\subsection{Experimental Design}

The system for double filtration was made by gluing a porous filter, $\mathrm{X}$, and the study filters, $\mathrm{F}$, in a polyvinyl chloride pipe of diameter $8 \mathrm{~cm}$ as shown in Figure 1. The contaminated water from the reservoir was maintained at a constant overhead water pressure by the overflow tube $\mathrm{T}$ as it was being filtered through $\mathrm{X}$ to the space above F. Filter $\mathrm{X}$ was made of ball clay, grogs and hardwood sawdust powders mixed in the ratios of 3:2:3 by volume. Filter, $\mathrm{X}$ was used to remove bigger suspended particles which would otherwise clog filter $\mathrm{F}$.

In single filtration, filter $\mathrm{X}$ was replaced by filter $\mathrm{F}$ and the contaminated water was filtered through it directly.

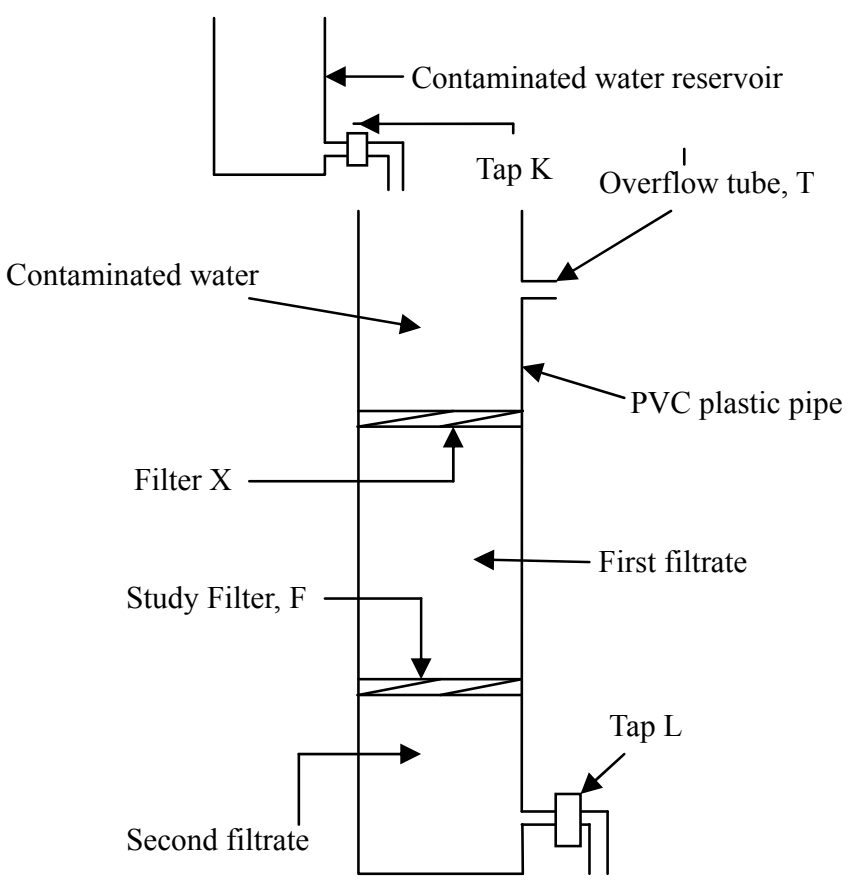

Figure 1. Experimental set up for double filtration

\subsection{Mechanisms of Water Flow Through CWF}

Permeability, diffusion and capillarity are the main mechanisms for water and water vapour flow through concretes and other ceramic materials although the dominant and fastest flow mechanism is capillary absorption (Skyer, 2005). By idealizing the pores in the ceramic filters as a network of conduits and then modeling the conduits as cylindrical tubes, the rate of flow of water, $Q$, i.e. volume per second, through the pores is given by Hagen-Poiseuille's Equation 1;

$$
Q=\frac{\pi d^{4}}{8 \mu} \frac{\Delta P}{\Delta L}
$$

where $\mu$ is the viscosity of water, $d$ is the average pore diameter and $\frac{\Delta P}{\Delta L}$ is the pressure gradient. 
Permeability is related to the rate of flow by Equation 2;

$$
K_{w}=\frac{Q d \rho_{w} g}{A\left(h_{1}-h_{2}\right)}
$$

where $K_{w}$ is permeability, A is cross section area, $\mathrm{d}$ is thickness, $\left(\mathrm{h}_{1}-\mathrm{h}_{2}\right)$ is pressure difference, $\rho_{w}$ is the density of water., The rate of flow of water, $Q$, is also given by Equation 3;

$$
Q=\frac{K_{w} A \Delta P}{\mu \Delta X}
$$

where $\Delta P$ is the pressure drop and $\Delta X$ is the depth of the sample in the test bed.

Meanwhile, the diffusion rate can be determined using Fick's first law expressed in Equation 4;

$$
J=-D \frac{d C}{d x}
$$

where $J$ is the mass of flux of the fluid, $D$ is the diffusion coefficient and $\frac{d C}{d x}$ is the concentration gradient.

\subsection{E. coli Removal and Water Turbidity}

Turbidity, which is a measure of the relative clarity of a liquid, is an optical characteristic of water and is an expression of the amount of light that is scattered by materials in water when light is shone through the water sample. Water with higher amounts of suspended particles produces higher intensity of scattered light and hence higher turbidity (USEPA, 1991). Excessive turbidity, or cloudiness, in drinking water is aesthetically unappealing, and may also represent a health concern. Turbidity can provide shelter and breeding ground for pathogens including E. coli. If not removed, turbidity can promote regrowth of pathogens in the distribution system, leading to waterborne disease outbreaks, which may cause significant cases of gastroenteritis throughout the world according to United States Environment Protection Agency (USEPA, 1991). Although turbidity is not a direct indicator of health risk, numerous studies show a strong relationship between removal of turbidity and removal of protozoa (Gregory, 1998). The particles of turbidity provide "shelter" for microbes by reducing their exposure to attack by disinfectants. Microbial attachment to particulate material has been considered to aid in microbe survival (Marshall, 1976). Thus due to their undesired health effects both the E. coli and other suspended particles need to be removed from domestic water before use.

2.6 E. coli Removal Efficiency Tests

E. coli are a member of the normal intestinal flora (Jawetz et al., 2010) although they are also the main cause of many clinically important intestinal infections. The percentage $E$. coli removal efficiency of the filters from the raw data obtained were calculated using Equation 5.

$$
\text { Percentage Removal Efficiency }=\frac{\text { Untreated }- \text { Treated }}{\text { Untreated }} \times 100 \%
$$

Where Untreated refers to microbial (E. coli) concentration in the raw water sample (Neat) in colon forming units per milliliter (cfu/ml) and Treated refers to microbial (E. coli) concentration in the filtered water sample in $\mathrm{cfu} / \mathrm{ml}$. These were obtained by counting the number of colonies of $E$. coli forming units on a glass petri-dish prepared under normal procedures by serial dilution.

\section{Results and Discussion}

\subsection{Results for Rate of Water Percolation Through the Study Filters}

The results for the average rate of water percolation through the study filters for both single and double filtration mechanisms are presented in Figure 2 and Table 1, and Figure 3 and Table 2, respectively. 


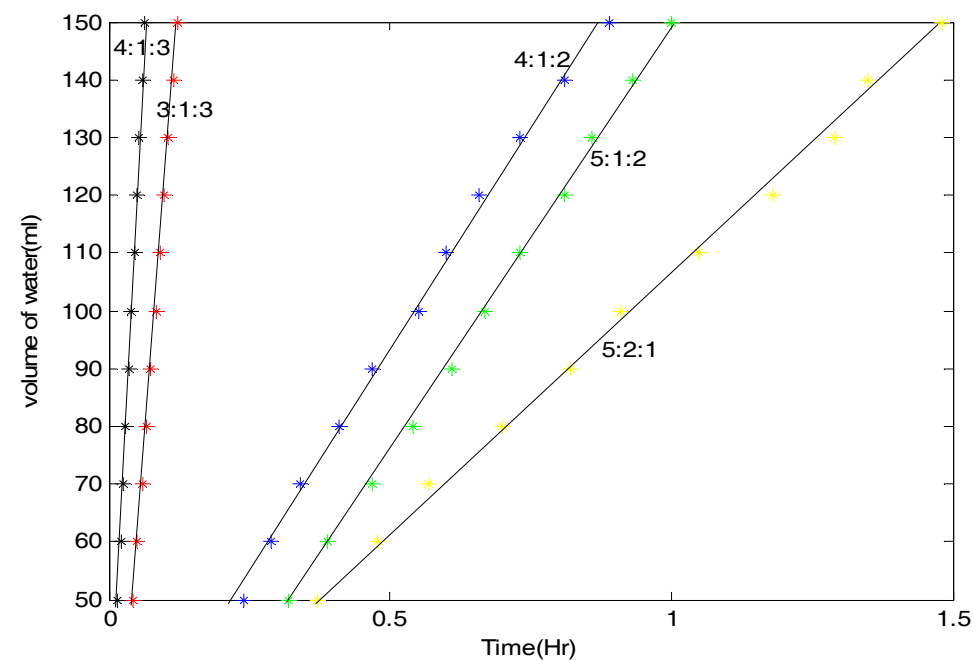

Figure 2. Graph of rate of water percolated through the study filters by single filtration mechanism

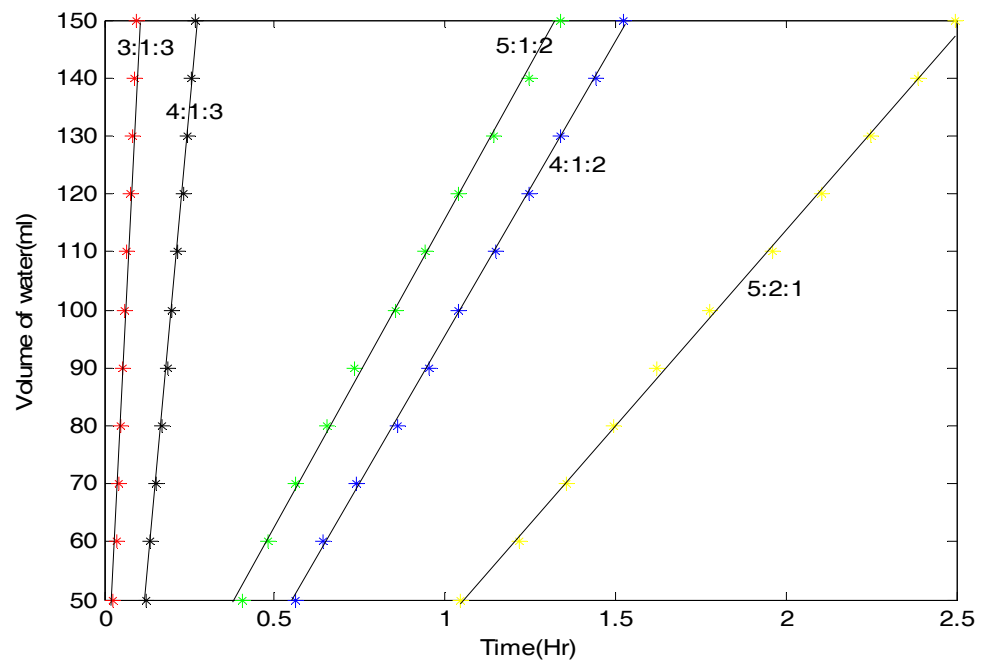

Figure 3. Graph of rate of water percolation through the study filters by double filtration mechanism

Table 1. Average rate of water percolation through the study filters for single filtration mechanism

\begin{tabular}{cc}
\hline $\begin{array}{c}\text { Composition ratio } \\
\text { (clay:grog:sawdust) }\end{array}$ & $\begin{array}{c}\text { Average rate of water percolation through the study } \\
\text { filters by single filtration mechanism }\left(\mathrm{ml} \mathrm{h}^{-1}\right)\end{array}$ \\
\hline $3: 1: 3$ & $1,230.00$ \\
$4: 1: 3$ & $2,070.00$ \\
$4: 1: 2$ & 161.29 \\
$5: 1: 2$ & 142.86 \\
$5: 2: 1$ & 090.91 \\
\hline
\end{tabular}


Table 2. Average rate of water percolation through the study filters for double filtration mechanism

\begin{tabular}{cc}
\hline $\begin{array}{c}\text { Composition ratio } \\
\text { (clay:grog:sawdust) }\end{array}$ & $\begin{array}{c}\text { Average rate of water percolation through the study } \\
\text { filters by double filtration mechanism }\left(\mathrm{ml} \mathrm{h}^{-1}\right)\end{array}$ \\
\hline $3: 1: 3$ & $1,271.00$ \\
$4: 1: 3$ & 606.10 \\
$4: 1: 2$ & 104.10 \\
$5: 1: 2$ & 106.70 \\
$5: 2: 1$ & 52.44 \\
\hline
\end{tabular}

\subsection{Discussion of Results for Rate of Water Percolation Through the CWF Discs by Single Filtration Mechanism}

From Figures 2 and 3, and Tables 1 and 2, the results show that for both single and double filtration mechanisms, the rate of water percolation is higher for filters with a high proportion of sawdust. This is because more pores are formed when the green bodies of filters with high proportions of sawdust are fired (Clair, 2006; Dies, 2003).

Similarly, from Figures 2 and 3, and Tables 1 and 2, the results show that the average rate of water percolation through filter $\mathrm{F}$ was higher for single than for double filtration mechanism because in a single filtration mechanism, it was easy to maintain a constant overhead water pressure above filter $\mathrm{F}$. While in double filtration mechanism, it was difficult to maintain a constant overhead water pressure between filters $\mathrm{X}$ and $\mathrm{F}$. This was because the filtrate through $\mathrm{X}$ was simultaneously being filtered through $\mathrm{F}$.

In addition, the percolation rate is lower in double filtration mechanism because the particle laden water has to navigate through intricate maze of labyrinths in two filters instead of one (Crittenden et al., 2005). Also where more grogs were added than sawdust for the same proportion of clay, the filtration rate was low because grog increases the labyrinths to be followed by the filtrate (Sagara, 2002).

A two-sample $t$ test was carried out to determine whether the rate of water percolation was actually higher for the single filtration mechanism compared to the double filtration mechanism at a level of significance of 0.05 . The calculated $t$-value obtained was -0.667 while the theoretical value was -1.860 at a degree of freedom 8 . Since the calculated $t$-value is greater than the theoretical $t$-value, it implies that there is a significant difference between the average rate of water percolation through the study filters in single filtration mechanism and double filtration mechanism.

\subsection{Results for Water Turbidity Tests and E. coli Removal Efficiency}

The results for water turbidity tests for single and double filtration mechanisms through the filters $\mathrm{F}$ are presented in Table 3 and Table 4, respectively.

Table 3. Results for water turbidity tests by single filtration mechanism

\begin{tabular}{cc}
\hline $\begin{array}{c}\text { Composition ratio } \\
\text { (clay:grog:sawdust) }\end{array}$ & $\begin{array}{c}\text { Average water turbidity in FNU per 10 ml } \\
\text { of water filtered by single filtration }\end{array}$ \\
\hline $3: 1: 3$ & 8.40 \\
$4: 1: 3$ & 8.44 \\
$4: 1: 2$ & 2.14 \\
$5: 1: 2$ & 2.09 \\
$5: 2: 1$ & 1.19 \\
\hline
\end{tabular}


Table 4. Results for water turbidity tests by double filtration mechanism

\begin{tabular}{cc}
\hline $\begin{array}{c}\text { Composition ratio } \\
\text { (clay:grog:sawdust) }\end{array}$ & $\begin{array}{c}\text { Water turbidity in FNU per 10ml of } \\
\text { water filtered by double filtration }\end{array}$ \\
\hline $3: 1: 3$ & 5.80 \\
$4: 1: 3$ & 5.36 \\
$4: 1: 2$ & 1.05 \\
$5: 1: 2$ & 1.41 \\
$5: 2: 1$ & 0.93 \\
\hline
\end{tabular}

Similarly, the results for the percentage E. coli removal efficiencies for both single and double filtration mechanisms are presented Table 5 and Table 6 .

Table 5. Results for E. coli removal efficiency by single filtration

\begin{tabular}{cc}
\hline $\begin{array}{c}\text { Composition ratio } \\
\text { (clay:grog:sawdust) }\end{array}$ & $\begin{array}{c}\text { Percentage } E \text {. coli removal efficiency } \\
\text { by single filtration mechanism }\end{array}$ \\
\hline $3: 1: 3$ & 99.3 \\
$4: 1: 3$ & 86.5 \\
$4: 1: 2$ & 100.0 \\
$5: 1: 2$ & 99.6 \\
$5: 2: 1$ & 98.7 \\
\hline
\end{tabular}

Table 6. Results for E. coli removal efficiency by double filtration

\begin{tabular}{cc}
\hline $\begin{array}{c}\text { Composition ratio } \\
\text { (clay:grog:sawdust) }\end{array}$ & $\begin{array}{c}\text { Percentage } E \text {. coli removal efficiency } \\
\text { by double filtration mechanism }\end{array}$ \\
\hline $3: 1: 3$ & 100.0 \\
$4: 1: 3$ & 092.0 \\
$4: 1: 2$ & 100.0 \\
$5: 1: 2$ & 099.7 \\
$5: 2: 1$ & 099.8 \\
\hline
\end{tabular}

\subsection{Discussion of the Results for Water Turbidity Tests and E. coli Removal Efficiency}

The results in Tables 3 and 4 show that double filtration mechanism lowered the turbidity of the filtered water compared to single filtration mechanism. At the same time, from Tables 5 and 6 , double filtration mechanism was seen to increase the E. coli removal efficiency of the filters compared to the single filtration mechanism. This is because during double filtration mechanism, there is increased zigzag channel (labyrinths) through which the water passes (Sagara, 2002). As a consequence, the suspended particles and E. coli get trapped in the filters by the mechanism of direct interception or sieving or bridging or inertial impaction or a combination of them as explained below.

Direct interception or sieving process occurs when a particle of size $0.5 \mu \mathrm{m}$ and larger "runs into" a pore at the topmost layer of the ceramic filter that is smaller than the particle and is captured as with absolute pore rated synthetic dead-end membranes as illustrated in Figure 4 (Farahbakhsh \& Smith, 2004). 


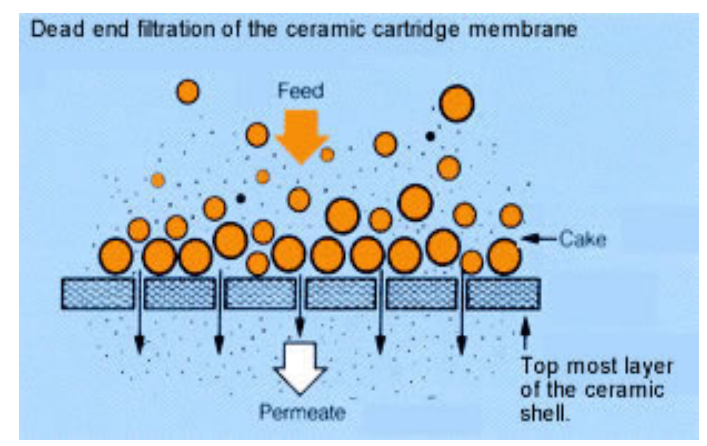

Figure 4. Direct interception or sieving

Adopted from Doulton Water Filter Ceramic Candle \& Cartridge Technologies (Doulton USA, 2010).

Particles of sizes smaller than $0.5 \mu \mathrm{m}$ may be too small to be intercepted. However, during the bridging process, when two smaller particles hit the obstruction at the same time, they will form a bridge across the pore by adhering to each other. Bridged particles may not block the pore but create an even smaller pore gradually forming a "filter cake" as shown in Figure 5.

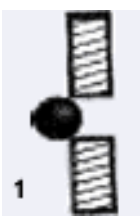

Figure 5. Bridging

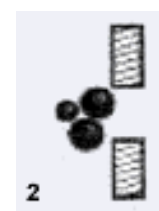

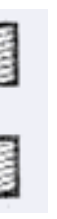

(1)

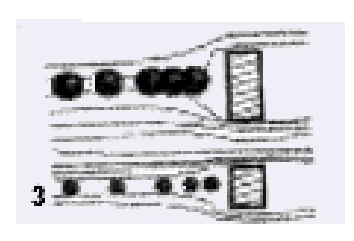

Figure 6. Inertial impact

Adopted from Doulton Water Filter Ceramic Candle \& Cartridge Technologies (Doulton USA, 2010).

This "cake" creates a finer filtration for subsequent interception at the cost of decreased flow rate and eventually no flow rate. However, the topmost blocked layer can be removed with a stiff brush or nylon scouring pad. This can be repeated many times before the filter has to be changed.

Furthermore, when a particle flowing through the filter hits a non-porous surface barrier, it becomes captured (Kenneth, 2008) while the water flows around the barrier as shown in Figure 6. This phenomenon is called inertial impaction and is more prevalent with smaller particles in range of $0.1 \mu \mathrm{m}$ to $0.4 \mu \mathrm{m}$ size as these particles are easily affected by molecular bombardment.

Much smaller suspended particles are intercepted within the filters by the ceramic depth filtration mechanism where the particle laden water navigates through an intricate maze of labyrinths as in Figure 7 (Crittenden et al., 2005)

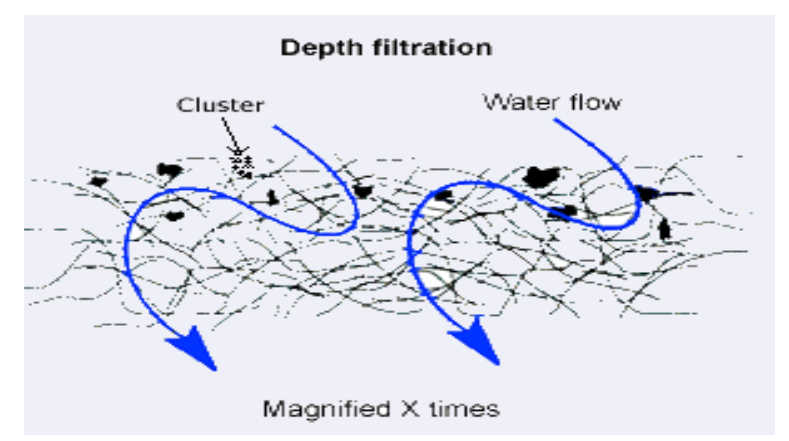

Figure 7. Depth filtration

Adopted from Doulton Water Filter Ceramic Candle \& Cartridge Technologies (Doulton USA, 2010). 
The water paths through the filters twist and turn through sharp angles due to the complicated ceramic structure (Sagara, 2002) and so the particles that may have penetrated the topmost layer become trapped within the structure. Small particles can combine with other particles to form a cluster of particles large enough to become trapped as a group or individual in dead end cavities. In addition, weak Van der Waals forces attract the small suspended particles to the ceramic, causing them to be adsorbed onto the wall of the ceramic.

In double filtration mechanism, the effects of the above filtration mechanisms were more pronounced since the filtrate had to pass through two filters, $\mathrm{X}$ and $\mathrm{F}$. This was supported by the observations that filter $\mathrm{F}$ with composition ratio $3: 1: 3$ by volume presented a percentage $E$. coli removal efficiency of $99.3 \%$ and $100.0 \%$ for single and double filtration mechanisms, respectively. Similar improvements were noted for all the other composition ratios of filters. Similarly, the turbidity of the filtrate was in the range of $1.19 \mathrm{FNU}$ to $8.40 \mathrm{FNU}$ for single filtration mechanism and $0.93 \mathrm{FNU}$ to $5.80 \mathrm{FNU}$ for double filtration mechanism again showing that double filtration mechanism improved the turbidity of the filtrate. Notably also, the test results for turbidity and E. coli removal efficiency for double filtration mechanism were within the recommended standards for drinking water by USEPA and WHO guidelines.

A two-sample $t$ test was carried out to determine whether the water turbidity actually improved for the double filtration mechanism compared to the single filtration mechanism at a level of significance of 0.05 . The calculated $t$-value obtained was -0.878 while the theoretical value was at -1.860 for a degree of freedom of 8 . Since the calculated $t$-value is greater than the theoretical $t$-value, it implies that there is a significant difference between the water turbidity resulting from the water filtered through the study filters in single filtration mechanism and double filtration mechanism.

\section{Conclusion}

This paper presented the results of an experimental study of water percolation and E. coli removal by double CWFs made by sintering of well controlled mixtures of clay, sawdust and grogs. The best quality water was obtained for double filtration when the filter composition ratio for clay: grog: sawdust was 5:2:1. This was followed by a composition ratio of 4:1:2. The water turbidity in FNU per $10 \mathrm{ml}$ of water filtered through these two filters by double filtration was 0.93 and 1.05 , respectively (Table 4). Similarly, E. coli removal efficiency for these two sets of filters was $100 \%$ and $99.8 \%$, respectively (Table 6). However, the numbers of small particles that combine with each other particles to form a cluster of particles tend to multiply rapidly over time.This may lower the efficiency of CWF with regard to $E$. coli removal. It is important that colloidal silver (Beden et al., 2013) would be essential to prevent this from happening.

Further analytical study of the filters needs to be done using scanning electron microscope in order to understand structures of the micrographs. Salient conclusions arising from this work include:

i Much more proportion of grogs to clay, improves on the filtration rate, but at the expense of the quality of water filtered.

ii Double filtration has much more effects on the quality of water filtered than single filtration.

\section{Acknowledgments}

I acknowledge the support accorded to me by the staff of Physics Department - Kyambogo University; the staff of the Department of Ceramics - Uganda Industrial Research Institute (UIRI); the staff of Physics Department Makerere University, and the staff of the Department of Biomolecular Resources and Biolab Sciences at the College of Veterinary Medicine, Animal Resources and Biosecurity - Makerere University, for allowing me to use the facilities in their laboratories during this study.

\section{References}

Beden, S. J., Dambus, H. I., Atiyah, R. I., Hashim, H. S., Ahmad, H. A., Mahi, W. A., ... Sumom, N. A. (2013). Nanotechnology in the edge of convergence. NAM S\&T Centre. Centers for Disease Control and Prevention 1600 Clifton Rd. Atlanta, GA 30333, USA 800-CDC-INFO (800-232-4636) TTY: (888) 232-6348.

Brooks, G. F., Carroll, K. C., Butel, J. S., \& Morse, S. A. (2010). Jawetz, Melnick, \& Adelberg's Medical Microbiology (24th edition by Vishal). The McGraw-Hill Companies.

Clair, M. (2006). House hold ceramic filter evaluation using three simple low cost methods: membrane filtration, $3 m$ Petri film and Hydrogen sulphide bacteria in Northern region Ghana. Msc thesis - Massachusetts Institute of technology (USA).

Crittenden, J. C. (2005). Water treatment: Principles and design. (2nd ed.). New Jersey: John Wiley \& Sons Inc. 
Doulton USA. (2010). Doulton Water Filter Ceramic Candle \& Cartridge Technologies. Retrieved from http://doultonusa.com/HTML\%20pages/technology.htm

Farahbakhsh, K., \& Smithe, D. W. (2004). Removal of Coliphages in Secondary Effluent by Microfiltration-Mechanism of Removal and Impact of operating Parameters. Walter Research, 38, 585-592. http://dx.doi.org/10.1016/j.watres.2003.10.018

Gregory, J. (1998). Turbidity and beyond. Filtration \& Separation, 35(1), 63-67. http://dx.doi.org/10.1016/S0015-1882(98)90665-6

Hans-wolf, R., \& Martin, J. (1998). Permeability, Diffusion and Capillarity absorption of concrete at elevated temperatures. Otto-Graf-Journal, 9, 34-47.

Kabagambe, M. (2010). Performance of ceramic water filters made from selected Ugandan clays for point-of-use. Masters dissertation. Makerere University, Kampala.

Katherine, L. C., \& Lauren, E. F. (2000). Implementation of an appropriate house-hold water purification system in Tourou, Cameroon. Retrieved November 17, 2010, from http://www.sys.virginia.edu

Kenneth, D. K. (2008). Water Treatment Plant Operation, Volume 1 (6th ed.). California State University (USA).

Kingery, W. D., Bowen, H. K., \& Uhlmann, D. R. (1976). Introduction to ceramics. (2nd ed.). New York: John Wiley \& Sons, Inc.

Kirabira, J. B. (2005). Properties of Ugandan minerals and fireclay refractories. PhD Thesis in material science. Stockholm, Sweden.

Kosek, M., Bern, C., \& Guerrant, R. L. (2003). The global burden of diarrhoeal disease, as estimated from studies published between 1992 and 2000. Bull World Health Organ, 81, 197-204.

Lantagne, D. S. (2006). Investigation of the Potters for Peace colloidal silver impregnated ceramic filter: Report 2: Field investigations (April 6, 2010). Boston: Alethia Environment.

Marshall, K. C. (1976). Interfaces in microbial ecology. Cambridge, MA: Harvard University Press. http://dx.doi.org/10.4159/harvard.9780674423350

Matovu, F. (2012). The expenditure review for Uganda 2012. Directorate of Social Protection - Gender Ministry, Kampala.

Obwoya, K. S. (2004). Effects of microstructure on mechanical strength of selected clays from Uganda. $\mathrm{PhD}$ Thesis. Makerere University, Kampala.

Prajapati, H. G. (2002). Madhyapur Clay Crafts. In J. Low (Ed.).

Ragland, K. W., Aerts, D. J., \& Baker, A. J. (1991). Properties of wood for combustion analysis. Bio-Resource Technology Journal, 37, 161-168. http://dx.doi.org/10.1016/0960-8524(91)90205-X

Republic of Uganda; Ministry of Finance, Planning and Economic Development. Poverty Eradication Action Plan (2004/5-2007/8); pp. 182-188.

Robert, W. D. (2003). Development of a ceramic water filter for Nepal. Dissertation for Master in Civil and Environmental Engineering, MIT.

Rugang, C., Hong, C., \& Robert, W. B. (2004). Properties required for moisture transport by capillary, gravity and diffusion in potash beds. Ind. Eng. Chen. Res., 43, 5365-5571. http://dx.doi.org/10.1021/ie0499658

Sagara, J. (2000). Study of filtration for Point-of-Use Drinking Water in Nepal. Master of Engineering in Civil and Environmental Engineering, Massachusetts Institute of Technology.

Skyer, M. (2005). Analysis and comparison of sustainable water filters. EPD397 Technical report. Retrieved November 28, 2010, from http://pottersforpeace.org

Sobsey, M. D. (2002). Managing Water in the Home: Accelerated Health Gains from Improved Water Supply. Geneva: World Health Organization (WHO/SDE/WSH/02.07).

Uganda National Energy Balance. (2002). Ministry of Energy and Mineral Development, Kampala, Uganda. April, 2003.

USEPA. (1991). Volunteer lake monitoring: A methods manual. EPA 440/4-91-002. Office of Water, U. S. Environmental Protection Agency, Washington, DC. 
Water Supply and Sanitation in Uganda. (2010). In Wikipedia, the free encyclopedia. Retrieved December 20, 2010, from http://en.wikipedia.org/wiki/water_supply_and_sanitation_in_Uganda

WHO/UNICEF. (2010). Meeting the MDG Drinking Water and Sanitation Target: A Mid-Term Assessment of Progress. Geneva and New York: World Health Organization and UNICEF.

\section{Copyrights}

Copyright for this article is retained by the author(s), with first publication rights granted to the journal.

This is an open-access article distributed under the terms and conditions of the Creative Commons Attribution license (http://creativecommons.org/licenses/by/3.0/). 